\title{
Síndrome de Mayer-Rokitansky-Küster-Hauser: estigma, corpo, mídia e bioética
}

\author{
Mayer-Rokitansky-Küster-Hauser syndrome: stigma, body, mass media \\ and bioethics
}

Síndrome de Mayer-Rokitansky-Küster-Hauser: estigma, cuerpo, medios
de comunicación de masas y bioética

Daniela Amado Rabelo ${ }^{1, a}$

daniela.a.rabelo@gmail.com | https://orcid.org/0000-0003-3725-0858

Natan Monsores ${ }^{1, b}$

monsores@unb.br | http://orcid.org/o00o-0002-0293-8460

\footnotetext{
${ }^{1}$ Universidade de Brasília, Faculdade de Ciências da Saúde, Programa de Pós-graduação em Bioética. Brasília, DF, Brasil.

a Mestrado em Bioética pela Universidade de Brasília.

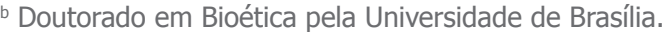

\section{Resumo}

O objetivo do estudo que fundamenta este artigo foi identificar e compreender a construção do estigma social relacionado à síndrome de Mayer-Rokitansky-Kuster-Hauser (SMRKH), uma condição que afeta exclusivamente mulheres. Analisou-se o conteúdo de 43 narrativas jornalísticas veiculadas eletronicamente. O desenho metodológico permitiu a identificação de três temas: (a) o tratamento anedótico da SMRKH; (b) a fragmentação anatomopatológica: mulher-útero ou mulher-vagina; e (c) a retórica do sofrimento da mulher redimido pela medicina. Cerca de $80 \%$ do corpus estavam centrados em questões biomédicas, além de haver um flerte com tecnologias experimentais e uma perspectiva de medicina paternalista. Concluiu-se, numa aproximação bioética centrada na dignidade humana, que há necessidade de rever a forma como a mídia apresenta as mulheres afetadas (mulher-útero), evitando ao mesmo tempo modelos de perfeição ou de normalidade que subsumam a mulher ao habitus mulher-esposa-mãe. As mulheres com SMRKH não são corpos ocos e sem úteros, são plenas e podem vivenciar a diferença.

Palavras-chave: Síndrome de Mayer-Rokitansky-Kuster-Hauser; Estigma; Corpo; Mídia; Bioética. 


\begin{abstract}
This article bases on a study to identify and understand the construction of social stigma related to Mayer-Rokitansky-Kuster-Hauser (MRKH) Syndrome, a condition that exclusively affects women, in 43 electronically transmitted journalistic narratives, using the content analysis, based on Laurence Bardin. The methodological design allowed the emergence of three themes: (a) the anecdotal treatment of MRKH syndrome; (b) the anatomopathological fragmentation: woman-uterus or woman-vagina; and (c) the rhetoric of the suffering of the woman redeemed by doctors in medicine. About $80 \%$ of the corpus focused their attention on biomedical issues, and there was a flirtation with experimental technologies and a perspective from paternalistic medicine. Based on a bioethical approach centered on human dignity, it was concluded that there is a need to review the way in which the media presents the affected women (womanwomb), avoiding models of perfection or normality that subsume women to the woman-wife-mother characterization. Women affected by MRKH syndrome are not hollow and without uterus bodies, they have plenitude and can experience the difference.
\end{abstract}

Keywords: Mayer-Rokitansky-Kuster-Hauser syndrome; Stigma; Body; Media; Bioethics.

\title{
Resumen
}

El objetivo del estudio en el cual se funda este artículo ha sido identificar y comprender la construcción del estigma social relacionado con el síndrome de Mayer-Rokitansky-Kuster-Hauser (MRKH), una condición que afecta exclusivamente a las mujeres. Utilizando el análisis de contenido, basado en Laurence Bardin, fueron analizadas 43 narrativas periodísticas transmitidas electrónicamente. El diseño metodológico permitió la identificación de tres temas: (a) el tratamiento anecdótico del síndrome de MRKH; (b) la fragmentación anatomopatológica: mujer-útero o mujer-vagina; y (c) la retórica del sufrimiento de la mujer redimido por la medicina. Cerca del 80\% del corpus estabam centrados en cuestiones biomédicasy mostraron flirteo con tecnologías experimentales y una perspectiva de medicina paternalista. Se concluyó, en una aproximación bioética centrada en la dignidad humana, que existe la necesidad de revisar la forma como los medios presentan a las mujeres afectadas (mujer-útero), evitando modelos de perfección o de normalidad que subsuman a la mujer a la caracterización mujer-esposa-madre. Las mujeres con síndrome de MRKH no son cuerpos huecos y sin úteros, son plenas y pueden experimentar la diferencia.

Palabras clave: Síndrome de Mayer-Rokitansky-Kuster-Hauser; Estigma; Cuerpo; Medios de comunicación de masas; Bioética.

Contribuição dos autores:

Todos os autores se envolveram igualmente nas etapas de construção do trabalho: concepção e desenho do estudo; aquisição, análise ou interpretação dos dados; redação do manuscrito; revisão crítica do conteúdo intelectual.

Declaração de conflito de interesses: não há.

Fontes de financiamento: não houve.

Considerações éticas: não há.

Agradecimentos/Contribuições adicionais: não há.

Histórico do artigo: submetido: 25 jan. 2018 | aceito: 16 abr. 2019 | publicado: 28 jun. 2019.

Apresentação anterior: não houve.

Licença CC BY-NC atribuição não comercial. Com essa licença é permitido acessar, baixar (download), copiar, imprimir, compartilhar, reutilizar e distribuir os artigos, desde que para uso não comercial e com a citação da fonte, conferindo os devidos créditos de autoria e menção à Reciis. Nesses casos, nenhuma permissão é necessária por parte dos autores ou dos editores. 


\section{Introdução}

As doenças raras, particularmente aquelas de caráter genético e congênito que implicam em deficiências ou alterações corporais, são historicamente acompanhadas por estigmatização e discriminação' ${ }^{1}$. Estigma é uma avaliação social negativa de uma característica particular ou de um comportamento ${ }^{2}$, geralmente acompanhado de um espectro de exclusão social ou de sofrimento individual e/ou familiar. Para Goffman³ ${ }^{3}$ há três grupos de estigma que compreendem dimensões anatomofisiológicas, somatopsicológicas e psicossociais. Em certas circunstâncias, parece haver sobreposição das três formas: a marca no corpo, a mudança no comportamento e novos regimes de pertencimento social. É o caso do grupo aqui estudado: mulheres que vivem com a síndrome de Mayer Rokitansky-Küster-Hauser (SMRKH).

A SMRKH é caracterizada pela agenesia vaginal (presença de 1/3 da vagina) e ausência de útero, ou presença desse órgão vestigial (útero rudimentar, ou seja, um que não tenha a estrutura convencional, sem diferenciação entre o corpo e o cérvix uterino) em três níveis que evoluem de acordo com seu comprometimento: tipo I (isolada), tipo II (associada) e uma derivação do tipo II (Mullerian duct aplasia, Renal dysplasia and Cervical Somite anomalies) ou MURCS, forma grave com alterações em rins e esqueleto ${ }^{4-6}$. A taxa de mulheres com a síndrome é estimada em um caso a cada 4.000-5.00o pessoas $^{6}$. Estudo retrospectivo de coorte na Dinamarca aponta, em sua população, prevalência de 1:4000.

As alterações físicas da SMRKH impactam a qualidade de vida das mulheres afetadas ${ }^{8}$. A doença costuma ser descoberta na adolescência, quando há ausência de menarca (primeira menstruação) ${ }^{9}$ e ocorre dor pélvica ${ }^{10,11}$ o que leva à busca de atendimento ginecológico. $O$ diagnóstico da condição põe em questão aspectos psicológicos e sociais, tais como a sexualidade e a reprodução, a compreensão desse corpo feminino diferente, da feminilidade e de uma corporeidade singular. Há, portanto, um relevante impacto psicossocial ${ }^{12}$ na vida dessas mulheres, o que pode levar ao isolamento social e afetivo ${ }^{13}$.

Por ser uma condição rara, a SMRKH tem sido abordada com ênfase em aspectos biomédicos. Há cerca de 400 artigos indexados (PubMed), desde a década de 1960, e a maioria trata de aspectos fisiopatológicos, genéticos, clínicos e cirúrgicos. Há poucos estudos sobre o impacto da síndrome na psiquê e na vida social das mulheres. Bean e colaboradores ${ }^{8}$ relatam que o enfoque centrado na doença pode afetar a experiência e o enfrentamento da condição por quem recebe o diagnóstico. Isso significa assumir que, para a otimização do cuidado, não se pode permitir que a perspectiva biomédica da SMRKH sobredetermine outros modos somáticos de atenção dessas mulheres, isto é, "as maneiras culturalmente constituídas de se estar atento ao e com o corpo, num meio intersubjetivo"14. O cuidado voltado para a saúde dessas mulheres não pode se restringir ao diagnóstico e à tentativa de reestabelecimento da 'normalidade' anatômica. Deve compreender o cuidar de si, a relação com o outro e os determinantes sociais e históricos associados ao 'ser mulher'. Mas, para isso, é preciso inferir como a síndrome é retratada fora do circuito biomédico, isto é, se há reprodução de uma visão centrada na patologia (na alteração anatômica ou na anormalidade) ou se as narrativas incorporam novos códigos e valores.

A fim de se estabelecer uma interface entre os aspectos biomédicos, sanitários e sociais presentes nas matérias jornalísticas analisadas, tomou-se como campo de análise teórica a bioética, compreendida como perspectiva multi-intertransdisciplinar ${ }^{16}$. A Declaração Universal sobre Bioética e Direitos Humanos (DUBDH), em seu Artigo 11, estabelece que a estigmatização é "violação à dignidade humana, aos direitos humanos e às liberdades fundamentais"17 . Conhecer esse cenário pode auxiliar as reflexões em saúde e o papel das instituições, especialmente da mídia, que é formadora de opinião pública e está sempre presente nos agendamentos pessoais. Refletir criticamente acerca do papel das narrativas midiáticas sobre 'as mulheres sem vagina' pode permitir a inclusão, de forma humana e responsável, de novas abordagens que reconduzam a mulher ao centro do cuidado e à sua ressignificação.

Para apreender parte dos discursos sociais associados à compreensão da SMRKH, é estratégico identificar como são construídas as narrativas midiáticas sobre quem vive com essa condição. Portanto, o objetivo da pesquisa aqui apresentada foi identificar e compreender a construção do estigma social relacionado à SMRKH, 
em narrativas jornalísticas veiculadas eletronicamente. Para isso, foi utilizada a análise de conteúdo, baseada em Bardin ${ }^{15}$. Após a conformação de um corpus de análise, buscou-se estabelecer como é construída a representação do estigma da mulher com SMRKH na e pela mídia. Tentou-se identificar quais signos, presentes nas narrativas midiáticas, promovem o desaparecimento do corpo feminino oferecendo, assim, outros significados, significantes e referentes. Por fim, tentou-se identificar até que ponto a linguagem midiática, de base factual e com premissa fática e de pressuposta neutralidade, promove a perpetuação de moralidades que reforçam estigmas.

\section{Estratégia metodológica}

Como já mencionado, realizou-se pesquisa documental (matérias jornalísticas veiculadas eletronicamente) e análise de conteúdo baseada em Bardin ${ }^{15}$. Para alcance de resultados, a pesquisa foi desenvolvida obedecendo as seguintes etapas ${ }^{18}$, conforme descrito por Silva e Fossá:

a) Leitura flutuante de documentos (matérias jornalísticas, posts em blogs, artigos científicos, textos de rede sociais) a fim de criar primeiras impressões sobre o tema;

b) Definição da pergunta de pesquisa (população, interesse e contexto - PICo);

c) Definição dos veículos de comunicação: consultaram-se os sites do Instituto Verificador de Circulação e do Guia de Mídiaii para identificação de jornais de maior audiência e circulação no Brasil. Como critérios de exclusão dos veículos nessa busca traçou-se: 1) plataforma sem lupa de busca; 2) site do veículo com erro de servidor ou não disponível; 3) acesso às matérias jornalísticas restrito aos assinantes; 4) veículos cujas matérias jornalísticas não tinham um teor factual; e 5) o assunto SMRKH apenas foi utilizado na narrativa para exemplificar outro tema central;

d) Estabelecimento de palavras-chave (descritores) para busca em mídia (jornais): o uso dos termos ‘Síndrome MRKH', 'Síndrome de Rokitansky' e 'Síndrome de Mayer-Rokitansky-Küster-Hauser' permitiu o reaparecimento de matérias jornalísticas;

e) Coleta das matérias jornalísticas: utilizou-se a função WebClipper do aplicativo Evernote ${ }^{\circledR}$ com uso de palavras-chave específicas em busca rápida, como o nome do veículo, cidade, estado e organização de datas (postagem e veiculação). Por conveniência, foi estabelecido o nexo temporal de cerca de seis anos para pesquisa documental, abrangendo o período de 01 de janeiro de 2011 a o1 de julho de 2017. É importante destacar que o tema SMRKH, como boa parte das doenças raras, não tem grande visibilidade midiática e, por isso, foi possível realizar coleta exaustiva de matérias jornalísticas no Brasil que veicularam reportagens sobre o assunto;

f) Leitura geral do material organizado no corpus;

g) Codificação (assistida pelos softwares Iramuteq e Nvivo) das unidades de registro para formulação de categorias de análise, mediante aporte do referencial teórico escolhido e indicações oriundas da leitura geral;

h) Recorte do material em unidades de registro (palavras, frases, parágrafos) comparáveis e com o mesmo conteúdo semântico;

i) Estabelecimento de categorias temáticas de análise (unidades de contexto);

j) Agrupamento das unidades de registro nas unidades de contexto com uma lógica de refinamento e agrupamento progressivo das categorias;

k) Inferência e interpretação, respaldadas no referencial teórico.

\section{Resultados e discussão}

A partir da utilização dos descritores definidos, 59 matérias jornalísticas foram selecionadas. Destas, 52 obedeceram aos critérios de inclusão previstos na pesquisa. Devido às repetições de conteúdo, o número total que compôs o corpus foi reduzido para 43.

i Disponível em: https://ivcbrasil.org.br/.

ii Disponível em: https://www.guiademidia.com.br/. 
A leitura geral das matérias jornalísticas permitiu identificar dois fenômenos: (a) há uma prática dos veículos em replicar - literalmente - conteúdos já disponibilizados por outras fontes, (b) uma parte das narrativas apresentadas tem como fonte artigos de veículos/agências internacionais que foram traduzidos e adaptados. Aparentemente, a reprodução acrítica de conteúdos sobre o tema é regra.

Nove matérias jornalísticas, cujo tema era primordialmente o impacto do diagnóstico da SMRKH, apresentaram as mesmas mulheres: (a) Jacqui Beck e Kelly Smith, ambas da Inglaterra, (b) Raiane Rodrigues e Michele Gehlen, do Brasil; e (c) Joanna Giannouli, da Grécia. As demais contextualizaram o tema e apresentaram a síndrome por um prisma biomédico, centrado em questões emergentes em bioética (Figura 1). Por questões emergentes compreende-se uma aproximação biotecnocientífica de temas de saúde ${ }^{16}$.

A pauta referente a 'transplante de útero' (Figura 2) foi apresentada em 18 das 34 matérias jornalísticas, com 132 repetições ao longo do corpus. Um quarto delas apresentou as biotécnicas para reconstrução de vaginas em laboratório. E cerca de 15\% trouxeram a questão da gravidez substitutiva ou cessão temporária. Isso significa que cerca de $80 \%$ do corpus estudado se centra em questões médicas, ou seja, há uma ênfase no aspecto anatomopatológico da SMRKH. Essa inferência se comprova com a avaliação da frequência de termos médicos no corpus: transplante (66 ocorrências), hospital (56 ocorrências), condição (53 ocorrências), paciente (50 ocorrências), órgão (44 ocorrências), células (41 ocorrências), tratamento (39 ocorrências), laboratório (38 ocorrências) e medicina (37 ocorrências) em um corpus com 43 matérias jornalísticas. Isso significa que alguns destes termos ocorrem mais de uma vez em uma mesma matéria.

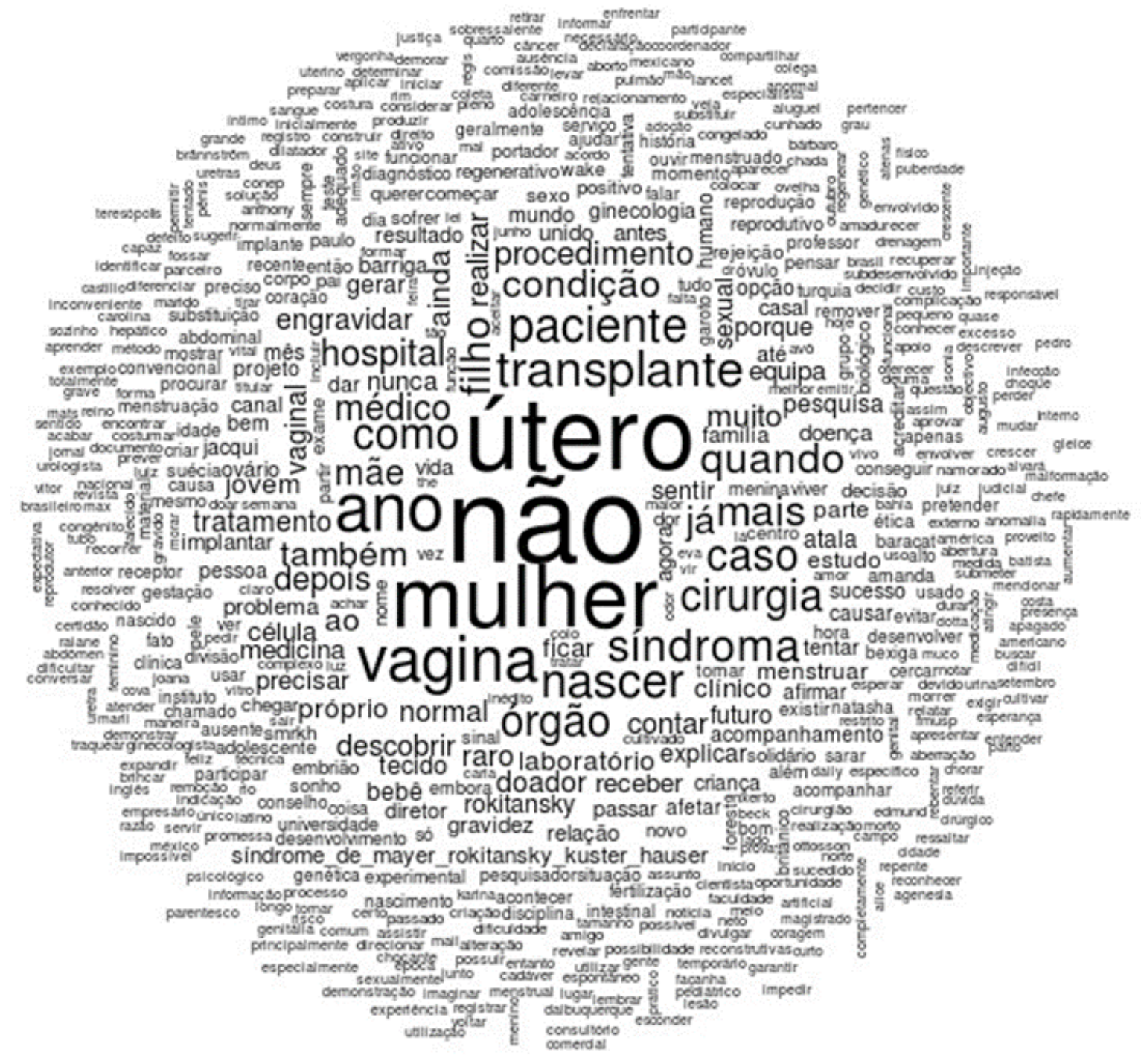

Figura 1 - Nuvem de palavras gerada a partir dos termos presentes no corpus

Fonte: Os autores (2018). 


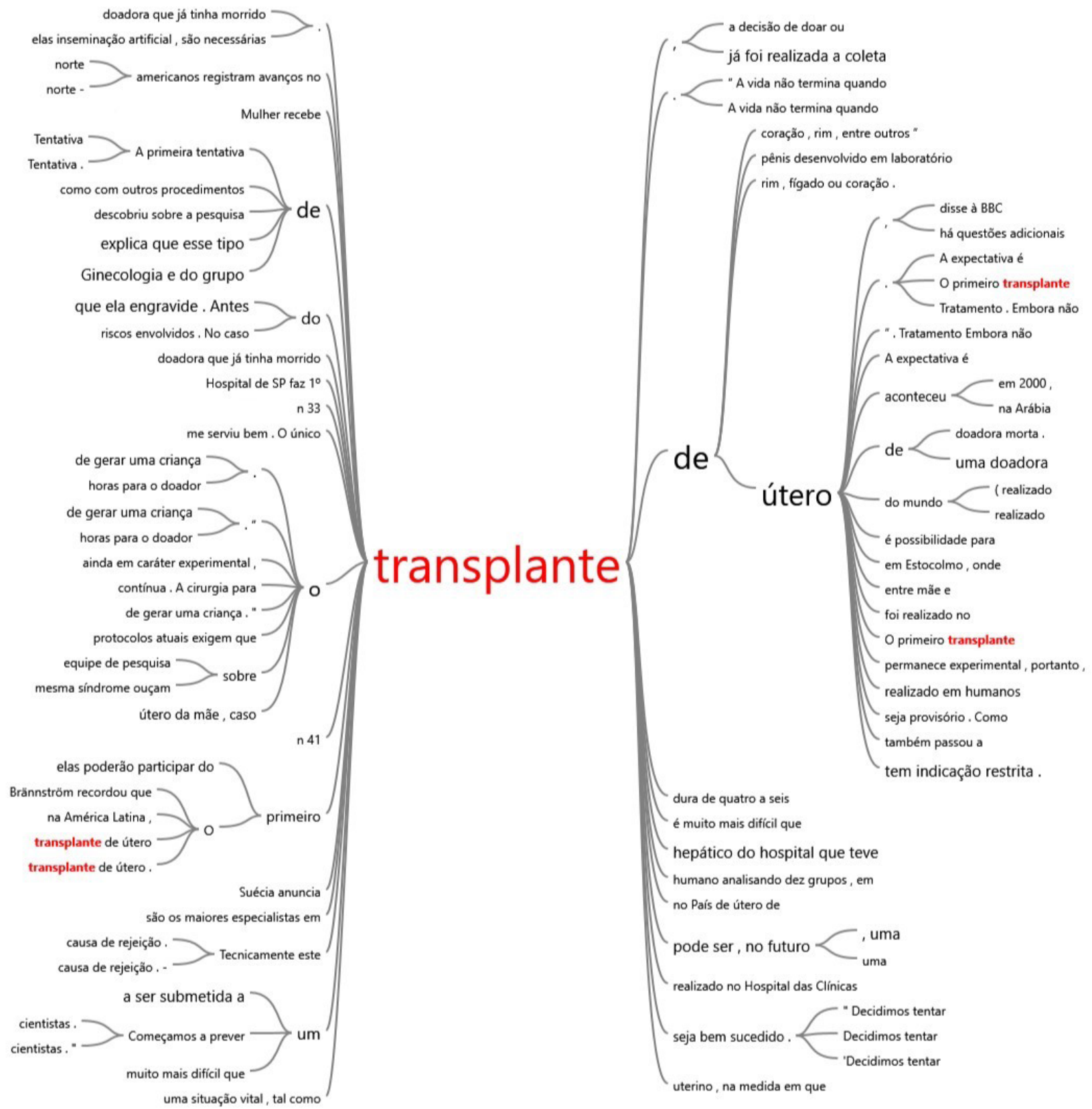

Figura 2 - Cluster de ocorrências da palavra transplante no corpus Fonte: Os autores (2018).

Após a análise de frequência, foi realizada a avaliação de co-ocorrências de palavras, como exemplificado na Figura 2. Foi construído um mapa com a análise das co-ocorrências e realizada uma análise de cluster para identificação de categorias temáticas presentes no corpus. Três temas emergem: (a) o tratamento anedótico da SMRKH; (b) a fragmentação anatomopatológica: mulher-útero ou mulher-vagina; e (c) a retórica do sofrimento da mulher redimido pela medicina.

\section{O tratamento anedótico da SMRKH}

A divulgação midiática de informações sobre condições genéticas ou doenças que têm como resultado alterações aparentes no corpo parece se apoiar na retórica do freak ou do freakshow ${ }^{19-22,}$ isso é, num padrão de espetacularização da característica física (que poderia ser social, racial, religiosa etc.) divergente daquilo que é definido como norma ou normal. O aspecto informativo das matérias jornalísticas, nos 
quais há detalhamento biomédico da SMRKH, é o pano de fundo para a exposição da 'mulher-sem-vagina' (em outras épocas teria sido 'mulher-barbada', 'mulher-lobo' etc.). O aspecto anedótico das matérias jornalísticas apresenta essas mulheres como curiosidades médicas (uma forma soft para a antiga designação de 'monstros'). O termo 'aberração' emerge nas falas das entrevistadas, revelando que, nas entrelinhas, o tratamento politicamente correto durante a escolha das palavras a serem usadas na construção das narrativas não consegue subsumir o reforço à estigmatização. A adoção desse tipo de linha editorial reforça a supersimplificação, a má representação e a subestimação dos custos pessoais e sociais da SMRKH, como já relatado no caso de doenças mentais e de Aids $^{23}$.

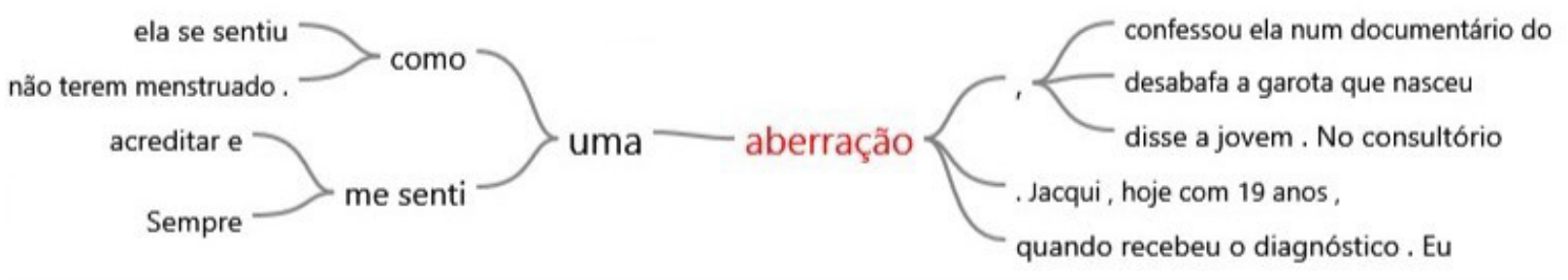

Figura 3 - Cluster de ocorrências da palavra aberração no corpus Fonte: Os autores (2018).

A apresentação das mulheres como 'as sem vagina ou as sem útero' é encontrada em cerca de $42 \%$ do corpus. Há certa conotação de inadequação de uma mulher que não pode ser mãe ou não pode manter relações sexuais, reforçando o ideário há muito tempo denunciado pelos estudos feministas ${ }^{23}$. Essa ideia de 'inadequação' é referenciada em estudos de pessoas que vivem com deficiências (disabilities studies). Às mulheres com SMRKH é atribuído um caráter assexual ou até mesmo de incompetência, o que parece ser a regra no tratamento dispensado a quem vive com deficiência ${ }^{24}$. Tal situação reforça o estigma, que pode se converter em formas de violência ou de injustiça epistêmica ${ }^{25}$, e, consequentemente, de exclusão social, elevando-se a potência discriminatória contra uma mulher-útero (tema b) e de uma mulher que deve ser corrigida (tema c) para tentar se adequar aos padrões de normalidade. De alguma forma, trata-se de capacitismo (ableism), palavra-referência na área de estudos de deficiências, que designa a discriminação aos "sem capacidade" 26 , na presente análise, a incapacidade de ter filhos, a incapacidade de menstruar ou de fazer sexo. Segue um trecho, presente na matéria jornalística número 27, que demonstra como ela reforça a concepção de inadequação ao habitus mulher-esposa-mãe: "A condição faz com que ela não tenha útero nem vagina, apesar de ter ovários normais. A demora na identificação do problema é comum em casos como o de Jacqui, já que a aparência externa do órgão genital é completamente normal. A diferença é que, no lugar onde deveria haver a abertura vaginal, existe apenas uma pequena cavidade. Por esse motivo, as pacientes descobrem a síndrome somente quando tentam fazer sexo ou quando procuram um médico para investigarem o fato de ainda não terem menstruado. 'Como uma aberração'. Jacqui, hoje com 19 anos, conta que ela se sentiu 'como uma aberração' quando recebeu o diagnóstico. "Eu nunca tinha me considerado diferente de outras mulheres e a notícia foi tão chocante que eu não podia acreditar no que estava ouvindo. Tive certeza de que a médica havia cometido um erro, mas quando ela explicou que era por isso que eu não estava menstruando, tudo começou a fazer sentido", diz a jovem. Jacqui conta que a médica também explicou que ela nunca poderia ficar grávida e poderia ter de passar por uma cirurgia antes de poder fazer sexo. "Saí do consultório chorando. Eu nunca saberia como seria dar à luz, estar grávida, estar menstruada. Todas as coisas que eu me imaginava fazendo de repente foram apagadas de meu futuro." Ela chegou a pensar que não era mais uma 'mulher de verdade'. Como ela nunca havia tentado fazer sexo, não descobriu o problema antes. Mas, se tivesse tentado, descobriria ser impossível concretizar a relação.”27 


\section{A fragmentação anatomopatológica: mulher-útero ou mulher-vagina}

O segundo tema, encontrado durante a apuração das matérias jornalísticas, é decorrente de outro paradigma: o da centralidade do pensamento biomédico em todas as esferas da vida, com certa redução ou colonização técnica de aspectos do viver humano ${ }^{28}$. Há certo privilégio do aspecto técnico ou médico no corpus, como já demonstrado. À primeira vista, esta priorização cumpre o aspecto informativo da matéria jornalística. Entrega, ao leitor, uma descrição das características mais aparentes ou detectáveis, como mostra a matéria jornalística número 20: "A condição se refere a mulheres que nascem com vagina, colo do útero e útero subdesenvolvidos ou ausentes. Mulheres com essa síndrome têm ovários e genitália externa (vulva), desenvolvendo também pelos púbicos e seios. Um dos primeiros sinais da síndrome é que uma menina não menstrua. O sexo também é dificultado porque a vagina é mais curta que o normal.”29

Nas matérias jornalísticas, há certa imprecisão sobre o significado de vagina na manifestação congênita da SMRKH. A síndrome afeta parte do canal vaginal (dois terços), conforme aponta a literatura científica ${ }^{6}$, mas as narrativas podem induzir certa confusão entre vulva e vagina, como já ocorre no imaginário popular. Vulva não é uma forma corrente de se referir a genitália externa feminina, e vagina acaba por compreender toda genitália. A distinção vulva (genitália externa) e vagina aparece em três matérias jornalísticas. Nos textos, a alteração anatômica é apresentada como "pequena cavidade" ou "covinha". É frequente outra imprecisão, que se refere a ausência de ovários ou gônadas, o que não ocorre na SMRKH ${ }^{30,31}$.

Outro ponto importante no corpus é o hype acerca da ausência de útero. Dois elementos são decorrentes do 'uterocentrismo' no corpus. O primeiro é que a mulher, sua corporeidade e seu corpo saem de cena. O segundo, que reforça o estigma, é que a ausência anatômica se verte em alguma falha de caráter que, neste caso, é a impossibilidade de ser 'mulher plena'. Na matéria jornalística número 30, afirma uma das mulheres entrevistadas: "[...] já tive um namorado que sabia que eu não podia ter filhos, mas nunca tive coragem de falar para ele do que se tratava de verdade. Acabo me isolando, prefiro assim." ${ }^{32}$

A expressão dessa plenitude ou de normalidade, é uma concepção que tem registro no século XIX e acaba por marcar relações assimétricas de poder (desigualdade) ${ }^{33}$. Na pós-modernidade há uma mudança de paradigma na compreensão do corpo. Se antes ele era construído a partir de uma comunidade, em uma perspectiva coletiva social, o corpo moderno é máquina ou mecanismo composto por partes. E pode ser reduzido, fragmentado, dividido para melhor controle ${ }^{34}$. Essa condição moderna é refletida no discurso midiático. $\mathrm{O}$ “império dos órgãos” 35 está na mídia e o sujeito é vertido num corpo que se encontra fragmentado em partes, órgãos, células ou moléculas.

No modelo biomédico, a comunidade ou a família sai do centro do cuidar e se enfraquecem enquanto instituições que amparam a convalescença ou a enfermidade. Em seu lugar, surgem os especialistas (médicos) que perscrutam as falhas que resultam na doença ${ }^{35.36}$. E estas falhas estão nos órgãos (ou nos genes), de tal forma, que o mix de informações sobre a síndrome, além de informar acerca da ausência de útero, de vagina ou de falha genética, reforça a concepção de que existe um 'padrão normal feminino' que não é possível sem o útero. De alguma forma, trata-se de situação similar àquela enfrentada por mulheres que tiveram câncer de mama ${ }^{37,38}$, para os quais a perda dos seios implica em ter diminuída sua condição de mulher. No caso da ausência de útero, pesa a lacuna no papel social de mãe biológica, que é encarado também como falha de caráter ${ }^{39}$, como ilustram as matérias 11 e 27. "Com o tempo, o apoio dos amigos, do meu parceiro, e com o apoio incondicional de minha mãe, sinto que sou uma pessoa de muita sorte, plenamente satisfeita” ${ }^{4}$. Ou ainda: "A síndrome pode ajudá-la a encontrar o homem certo, já que seu futuro parceiro terá que aceitá-la como ela é, o que para ela funcionará como um 'teste de caráter"”27.

Deve-se recordar que as anormalidades físicas são a condição a priori para o primeiro tipo de estigma apresentado por Goffman³ ${ }^{3}$ Ainda que, no caso específico da SMRKH, não seja possível às pessoas do entorno da mulher vê-las ou tocá-las, é possível materializá-las pelo relato ou pela leitura do texto. Assim, elas se 
tornam reais para o receptor, que lê esse material. Transitam aqui de uma pessoa antes desacreditável ${ }^{3}$ (com característica distintiva nem conhecida ou nem imediatamente evidente) para uma condição conhecida em nível de massa, tornando-se, assim, pessoa desacreditada ${ }^{3}$. Nas narrativas, as palavras compõem mensagens e não têm apenas sentido, elas são sentidas.

Em algumas matérias jornalísticas, como mostra a número 28, há tentativa de apresentar um resgate heroico da mulher sem útero que, assumindo de forma submissa o habitus mulher-esposa-mãe, buscará a aceitação masculina ainda que tenha uma 'falha de caráter': "Hoje com 19 anos e uma 'romântica incorrigível', Jacqui não vê a doença pelo lado ruim, mas diz que sua condição a ajudará a achar 'o cara', que a aceite como é. Ela afirma ainda que não esconderá a informação de nenhum dos namorados que vier a ter: 'me sinto mais confortável que eles saibam a verdade'."41.

A prescrição de uma condição de incapacidade prevalece, já que a sua 'anormalidade' não permite uma vida sexual plena e completa - ao menos até o seu corpo ser 'corrigido' pela ciência, segundo o que é veiculado de forma mais expressiva no corpus de análise da pesquisa.

Ao se refletir sobre como uma informação se propaga em massa, sujeita a apreensão de diferentes pessoas, em múltiplos espaços, deve-se refletir sobre como estabelecer condições para garantia de autonomia das mulheres com SMRKH, isto é, para que sejam apresentadas pela mídia de forma a reforçar experiências de corporeidade feminina que prescindam da 'presença do útero', como no caso das mulheres que passaram por histerectomia ${ }^{42}$. A dignidade humana é um dos pilares do pensamento bioético, de sorte que deve haver consideração moral sobre a condição de vulnerabilidade das mulheres portadoras da SMRKH, aqui subscrita numa perspectiva não paternalista, a fim de garantir que, longe de julgamentos valorativos mediados por uma concepção de normalidade, possam desenvolver plenamente sua autonomia e fazer escolhas quanto ao próprio corpo ${ }^{43}$.

\section{A retórica do sofrimento da mulher redimido pela medicina}

O terceiro tema frequente nas matérias jornalísticas é o do papel da medicina como agente de resgate da condição feminina. Csordas, um dos referenciais para a presente pesquisa, reflete: "O que significa ser um ser humano, inteiro e são, ou angustiado e doente?” (p.20) ${ }^{44}$. Não pretendemos traçar uma crítica sobre o papel do avanço do conhecimento médico na qualidade de vida geral da população. Não se pode prescindir de vacinas, antibióticos e cirurgias em determinadas situações de adoecimento. Mas é necessário destacar que, como todo saber constituído na modernidade, há certa ambiguidade nas práticas médicas. O saber que possibilita que uma mulher com SMRKH faça uma cirurgia, também cria o espaço para o estigma, na medida em que permite que um status corporal (a doença, ausência de um órgão, a deficiência) sobredetermine seu status de pessoa.

Também é importante pontuar que, no corpus, tanto o relato dessas mulheres, quanto o que se reproduz nas matérias jornalísticas, depende das escolhas do gatekeeper ${ }^{45}$, representado geralmente pelo editor-chefe, que, junto aos demais jornalistas, finaliza a produção de seus textos especializados. Esse é o formalismo das mídias tradicionais - o agendamento passa necessariamente por esse protagonista nas redações. O controle da imprensa se faz na prescrição do que se deve pensar e na circunscrição dos temas aos quais o leitor terá acesso. Assim, o controle da mídia se estende a um receptor que só dispõe, muitas vezes, daquele espaço como principal ou única fonte de informação sobre determinado tema.

Um aspecto relevante, e que potencializa a discussão, é a compreensão de que existe um frame de mídia, isto é, um enquadramento de notícias (com tema, ênfase, palavras, termos, expressões) do tipo 'mulher-útero' ou 'mulher-vagina' que cria um sistema de referências para a apreensão ou compreensão dos conteúdos. Nesse sentido, a escolha do texto ou da imagem não está centrada nas necessidades da mulher afetada pela condição. O enquadramento é estabelecido por uma relação de poder, isto é, numa perspectiva ideológica ditada pelo establishment, com suas prescrições narrativas acerca da normalidade do corpo feminino. 
Outro aspecto peculiar é a adoção de narrativas pantográficas que visam entreter ou promover um alívio frente às tensões que podem aparecer no processo de aquisição da mensagem midiática, já que se trata de uma condição de saúde crônica e com desdobramentos psicossociais relevantes. Quem acessa matérias dessa natureza, de acordo com a hipótese de usos e gratificações, talvez busque informações para o enfrentamento de problemas de saúde ou mesmo tenha criado um laço empático ou no âmbito dos afetos com as mulheres apresentadas, seja pela solidariedade devido ao sofrimento em seus itinerários terapêuticos, seja pela jornada de superação de adversidades.

A relação das palavras escolhidas nas matérias jornalísticas sugere um contexto que privilegia a doença, e que define a mulher com SMRKH como pessoa doente, ainda que em busca de superação de sua condição. Não há pretensão, neste artigo, de esgotar a análise de cada aspecto psico-sócio-sanitário da SMRKH. O que se pretende destacar é que existe uma formulação discursiva centrada numa concepção moral, que traz em si uma justificativa médica: a mulher sem útero (e considerada incompleta em sua condição de mulher) deve ser reabilitada ou resgatada. É um enfoque que induz a audiência a enxergar certo grau de incompetência (em ter filhos ou em fazer sexo) da mulher com SMRKH e que pode ser redimida pela medicina. E os aspectos freak e de redução anatomopatológica são condições para este enquadramento.

Construções como "ela se sentiu como uma aberração quando recebeu o diagnóstico" ou "é ela que se sente 'diferente' ao saber da síndrome" e ela "não podia acreditar no que estava ouvindo" ou ainda "Não era mais "uma mulher de verdade' e se sentiu 'totalmente chocada' ao descobrir que não tinha vagina" ou "carregou a vergonha ao diagnóstico e que não conseguiu contar aos amigos e familiares, e só depois à mãe, por e-mail”, reforçam a percepção de que o diagnóstico ou a descoberta da SMRKH prenuncia um ato autocondenatório, tal qual aquele vivido e expresso por outros grupos sociais estigmatizados, em condições diferentes de doença, como no caso do HIV/Aids. Termos como 'chocada', 'deprimida', 'com raiva', 'abandonada', 'sozinha', 'isolada', 'chateada', 'perturbada', 'confusa', 'diferente' são comuns nestas situações. O sentimento de abandono, de "se sentir muito sozinha" também é expresso em outro estudo ${ }^{46}$.

Compreendemos que a vulnerabilidade do ser humano é condição intrínseca, mas, no caso de mulheres que vivem com alguma condição crônica, há superposição de condicionantes históricos e sociais, que aumentam o nível de vulnerabilidade. Para a mulher com SMRKH, "a dor é íntima, certamente, mas também impregnada de social, de cultural, de relacional" (p.14) ${ }^{47}$. Ela é uma percepção própria sobre tudo que vive e sente, e tem reflexo no plano existencial, mas se soma aos julgamentos de outrem. Por isso, discursos redentores se tornam sedutores. E é desta forma que a medicina é apresentada no corpus, assim como há um flerte com tecnologias experimentais. No corpus, 13 matérias jornalísticas abordam o tema reconstrução de vaginas e 21 o transplante de útero. Somadas, constituem cerca de 65\% do corpus. Por exemplo, nas matérias 13: "Baracat [cirurgião-chefe do Hospital das Clínicas] explica que esse tipo de transplante pode ser, no futuro, uma opção a mais para as mulheres que nasceram sem útero e têm o sonho de gerar uma criança." ${ }^{48}$. E na matéria 39: "[...] emite liminar inédita na Bahia” (...) ‘de declaração de nascimento vivo de uma criança gerada no útero da avó materna fosse emitida em nome dos pais biológicos, que fizeram uma fertilização assistida com seu material genético'. 'Essa ação foi uma das que mais me emocionaram na minha carreira pelo fato de uma avó de quase 50 anos gerar o próprio neto para ajudar a filha a realizar o sonho de ser mãe."."48.

Há abundância de termos que se referem às tecnologias biomédicas para tratamento da SMRKH: 'empresta barriga', 'transplante de útero', 'barriga de aluguel', 'útero de substituição', 'implantou no útero', 'dois embriões fecundados', 'transplante mundial de útero entre mãe e filha', 'útero da mãe', 'fertilização in vitro', 'esperma de seu namorado', 'óvulos fertilizados', 'vagina artificial'.

Na matéria jornalística 22, observa-se a narrativa da "vagina artificial" que "mudou a sua vida [da paciente] também é frequente. Como relatado por uma das entrevistadas (não nominadas em uma matéria jornalística) desse "modelo experimental": "me sinto feliz por ter feito a cirurgia, porque agora posso ter uma vida normal". 
E reforça: "sei que sou uma das primeiras, mas é importante deixar claro para outras meninas que sofrem do mesmo problema que há um tratamento e que você pode ter uma vida normal"50.

Outra opção apresentada como forma de resgate das mulheres com SMRKH é o transplante de útero, a "possibilidade de substituir por barriga de aluguel”¹ (matéria jornalística 41), mas ela revela a necessidade de se "pesar benefícios e riscos" e "questões adicionais", "considerando que não é um transplante vital".

Há também apresentações de formas de resgatar a sexualidade, como a dilatação da vagina, contudo são menos exploradas nas matérias jornalísticas agregadas no corpus, já que a maternidade parece ser o foco. E isso é reforçado com construções narrativas como "esperança de ter uma família"40 (matéria 11), "saí do consultório chorando" ${ }^{2}$ (matéria 35), "eu nunca saberia como era dar à luz, estar grávida, estar menstruada"²7 (matéria 27), “Todas as coisas que me imaginava fazendo de repente foram apagadas de meu futuro"41 (matéria 28). Há também algumas contraposições, nas quais se pode observar a benção dos estigmatizados, prevista por Goffman ${ }^{3}$, como "tentar ver a sua condição de maneira positiva".

A condição de sofrimento posta ou a percepção de si como vítima das circunstâncias desloca o enfrentamento da condição para uma postura de fé no aspecto redentor da medicina, que se torna veículo para padrões mediados de sororidade ou de solidariedade e altruísmo, como se vê na matéria jornalística 37: "nós tivemos a chance de nos tornarmos mãe, e agora o nosso útero não nos serve mais. Poderemos doá-lo para quem realmente deseja" 33 .

Não queremos, aqui, adotar uma postura antimedicina, como já afirmado. Mas queremos destacar que a forma como a mídia apresenta a mulher, no contexto biomédico, precisa ser reenquadrada. Há um acúmulo teórico em bioética e em estudos sociais de ciência e tecnologia que permitem compreender a lógica paternal imbricada no agir médico ${ }^{54}$, assim como a tendência da grande mídia em reportar toda e qualquer tecnologia biomédica como boa (fetiche da tecnologia ${ }^{55}$ ). O saber médico não deve se impor à totalidade da experiência das mulheres com seus próprios corpos. Cada mulher, com ou sem SMRKH, vivenciou, em diferentes níveis, vulnerabilidade, desigualdade, discriminação ou opressão. Estas são reproduzidas nos discursos que se perpetuam nas agendas midiáticas. Há que se deslocar o enquadramento centrado no "corpo falido da mulher" para a valorização da diferença, do papel redentor do médico para a condição de possibilidade de vida digna da mulher, com útero ou sem útero ${ }^{56}$.

\section{Considerações finais}

O feminino, a sexualidade e a reprodução são temas recorrentes nos debates que envolvem mulheres afetadas por doenças crônicas. No caso da SMRKH, foi possível observar que a mídia impressa que circula no Brasil adota três enquadramentos para a questão: uma abordagem anedótica da SMRKH, isto é, valoriza o caráter de 'aberração' ou de situação médica peculiar que chama atenção do leitor; uma perspectiva de fragmentação anatomopatológica da mulher com SMRKH, havendo enfoque na condição de 'sem útero ou sem vagina', subsumindo a biografia da mulher à condição clínica; e, por fim, há uma sobrevalorização do papel da medicina enquanto agente de redenção da mulher em sofrimento, isto é, aquela que não é capaz de ter filhos ou de fazer sexo 'normal'.

Este é um estudo exploratório, no qual se buscou compreender a transposição ou circulação de discursos entre diferentes espaços sociais. Mas percebe-se que há aspectos éticos importantes que são acriticamente carreados na tradução ou na replicação de matérias jornalísticas sobre SMRKH. Entre esses estão a manutenção de um pensamento que desloca a mulher afetada para uma condição de vulnerabilidade, o que resulta em reforço do estigma da mulher que não possui útero, tal qual acontece com a mulher sem mama, a mulher obesa ou aquela acometida por HIV/Aids ${ }^{57-59}$. A fim de confirmar esses achados, seria importante realizar estudos mais próximos às comunidades de mulheres com SMRKH que têm se organizado nas redes sociais. 
Nossa leitura bioética, baseada numa concepção de dignidade humana, considera que existe uma necessidade de ressignificar a vivência dessas mulheres, de forma que profissionais de saúde e jornalistas, assim como a sociedade que recebe as informações pela mídia, compreendam que não se tratam de corpos ocos e sem úteros, mas de mulheres plenas que vivenciam a diferença. A dignidade humana não é uma questão de mérito, de perfeição ou de normalidade, ela deve ser entendida como uma característica inerente ao ser humano.

\section{Referências}

1. Markel H. The stigma of disease: implications of genetic screening. Am J Med. 1992 ago; 93(2):209-15.

2. Ablon J. The nature of stigma and medical conditions. Epilepsy Behav. 2002;3(6, Supplement 2):2-9.

3. Goffman E. Estigma: notas sobre a manipulação da identidade deteriorada. Antropologia Social. 1988. 158 p.

4. Ledig S, Schippert C, Strick R, Beckmann MW, Oppelt PG, Wieacker P. Recurrent aberrations identified by array-CGH in patients with Mayer-Rokitansky-Küster-Hauser syndrome. Fertil Steril. 2011; 95(5):1589-94.

5. Wang Y, Lu J, Zhu L, Sun Z, Jiang B, Feng F et al. Evaluation of Mayer-Rokitansky-Kuster-Hauser syndrome with magnetic resonance imaging: Three patterns of uterine remnants and related anatomical features and clinical settings. Eur Radiol [Internet]. 2017 [citado 2019 maio 17];27(12):5215-24. doi: https://10.1007/s00330-017-4919-4

6. Petrozza JC. Mayer-Rokitansky-Küster-Hauser syndrome and associated malformations: are they as common as we think? Fertil Steril. 2016;106(5):1047-8.

7. Herlin M, Højland AT, Petersen MB. Familial occurrence of Mayer-Rokitansky-Küster-Hauser syndrome: a case report and review of the literature. Am J Med Genet Part A. 2014; 164(9):2276-86.

8. Bean EJ, Mazur T, Robinson AD. Mayer-Rokitansky-Kuster-Hauser syndrome: sexuality, psychological effects, and quality of life. J Pediatr Adolesc Gynecol [Internet]. 2009 [cited 17 may 2019];2009, 22(6):339-46. Available from: http://www.ncbi.nlm.nih.gov/pubmed/19589707

9. Bargiel-Matusiewicz K, Kroemeke A, Polańska K. The relationship between neuroticism, coping styles and emotions in women with Mayer-Rokitansky-Küster-Hauser syndrome: a moderated mediation analysis. Polish Psychol Bull. 2013; 44(1):1-8.

10. Fedele L, Bianchi S, Berlanda N, Bulfoni A, Fontana E. Laparoscopic creation of a neovagina and recovery of menstrual function in a patient with Rokitansky syndrome: a case report. Hum Reprod. 2006; 21(12):3287-9.

11. Doyle JOB, Laufer MR. Mayer-Rokitansky-Kuster-Hauser (MRKH) syndrome with a single septate uterus: a novel anomaly and description of treatment options. Fertil Steril. 2009;92(1):391.e17-9. doi: https:// doi.org/10.1016/j.fertnstert.2009.03.049

12. Heller-Boersma JG, Schmidt UH, Edmonds DK. A randomized controlled trial of a cognitive-behavioural group intervention versus waiting-list control for women with uterovaginal agenesis (Mayer-RokitanskyKuster-Hauser syndrome: MRKH). Hum Reprod. 2007; 22(8):2296-301.

13. Poland MET. Psychologic aspects of vaginal agenesis. J Reprod Med. 1985;30(4):340-4.

14. Mello CAA. Percepção, intervenção e cura: sobre modos somáticos de atenção e a prática da benzedura. Cienc Soc Relig. 2013;15(8):57-75.

15. Bardin L. Análise de conteúdo. São Paulo: Edições 70; 2009. 225 p.

16. Garrafa V. Reflexões bioéticas sobre ciência, saúde e cidadania. Rev Bioet. 2009;7(1).

17. Organização das Nações Unidas para a Educação, a Ciência e a Cultura. Declaração Universal sobre Bioética e Direitos Humanos [Internet]. 2005 [citado 2019 maio 17]. Disponível em: http://bvsms.saude. gov.br/bvs/publicacoes/declaracao univ bioetica dir hum.pdf

18. Silva AH, Fossá MIT. Análise de conteúdo: exemplo de aplicação da técnica para análise de dados qualitativos [Internet].In: $4^{\circ}$ Encontro de Ensino e Pesquisa em Administração e Contabilidade; 2013 nov. 3-5 [citado 2019 maio 17]; Brasília: Anpad; 2013. p. 1-14. Disponível em: http://www.anpad.org. br/admin/pdf/EnEPQ129.pdf 
19. Arcoverde R, Mendes B, Cunha GV, Azenha EM, Cristine V, Costa R et al. Show de horrores: a ciência por trás das aberrações. Rev Med Saúde Brasília. 2016; 5(2).

20. Royaume-Uni. Mental disorders and genetics: the ethical context. Conclusions and Recommendations. J Int Bioéthique. 12(89-92).

21. Bogdan R. Freak show: Presenting human oddities for amusement and profit. University of Chicago Press. 2014; 336 p.

22. Bedini LA. Modern day'freaks'?: the exploitation of people with disabilities. Ther Recrea J. 1991; 25(4):61-70.

23. Thachuk AK. Stigma and the politics of biomedical models of mental illness. IJFAB . 2011;4(1):140-63.

24. Ouellette A. Bioethics and disability: toward a disability-conscious bioethics. New York: Cambidge University Press; 2011.

25. Fricker M. Epistemic injustice: power and the ethics of knowing [Internet]. [Oxford]: Oxford Schlolarship Online; 2007 [citado em 06 jun. 2019]. Disponível em: https://www.oxfordscholarship.com/ view/10.1093/acprof:0so/9780198237907.001.0001/acprof-9780198237907

26. Edmonds DK. Congenital malformations of the genital tract and their management. Best Pract Res Clin Obstet Gynaecol. 2003;17:19-40.

27. Garota descobre aos 17 anos que não tem vagina. A Gazeta News [Internet]. 2013 [citado 09 maio 2017]. Disponível em: http://www.agazetanews.com.br/imprimir/77363.

28. Tabet LP, Martins VCS, Romano ACL, Sá NM, Garrafa V. Ivan Illich: da expropriação à desmedicalização da saúde. Saúde Debate. 2017;41(115):1187-98.

29. Mulher conta que descobriu aos 16 anos que nasceu sem útero e sem órgão íntimo. O Sul [Internet]. 2016 [citado 15 maio 2017]. Disponível em: http://www.osul.com.br/mulher-conta-que-descobriu-aos16-anos-que-nasceu-sem-utero-e-sem-orgao-intimo/

30. Oppelt P, Renner SP, Kellermann A, Brucker S, Hauser GA, Ludwig KS et al. Clinical aspects of MayerRokitansky-Kuester-Hauser syndrome: recommendations for clinical diagnosis and staging. Hum Reprod [Internet]. 2006; [cited 17 may 2019]; 21(3):792-7. doi: https://doi.org/10.1093/humrep/dei381

31. Oppelt PG, Lermann J, Strick R, Dittrich R, Strissel P, Rettig I et al. Malformations in a cohort of 284 women with Mayer-Rokitansky-Kuster-Hauser syndrome (MRKH). Reprod Biol Endocrinol. 2012;10:57.

32. "Sempre me senti uma aberração", desabafa a garota que nasceu com doença rara. Circuito Matogrosso [Internet]. 2014 [citado 09 maio 2017]. Disponível em: http://circuitomt.com.br/editorias/saude/46842sempre-me-senti-uma-aberracao-desabafa-a-garota-que-nasceu-com-doenca-rara.html

33. Bobbio N, Matteucci N, Pasquino G. Dicionário de política. Brasília: Editora Universidade de Brasília; 1998.

34. Foucault M. O nascimento da clínica. Rio de Janeiro: Editora Forense Universitária; 1967.

35. Le Breton D. Adeus ao corpo. Campinas, SP: Papirus; 2003.

36. Le Breton D. Antropologia do corpo e modernidade. 3. ed. Petrópolis, RJ: Vozes; 2013.

37. Quintana MA, Santos RLH, Russowsky ILT, Wolff LR. Negação e estigma em pacientes com câncer de mama. Rev Bras Cancerol. 1999; 45(4):45-52.

38. Silva Regis MF, Faria Simões SM. Dbiagnóstico de Câncer de Mama: sentimentos, comportamentos e Expectativas de Mulheres. Rev Eletrônica Enferm [Internet]. 2006; [citado 2019 maio 17]; 7(1):81-6. Disponível em: https://bit.ly/2Qd3XB2

39. Remennick L. Childless in the Land of Imperative Motherhood: Stigma and Coping Among Infertile Israeli Women. Sex Roles. 2000; 43(11/12):821-41.

40. Nascida sem vagina, mexicana revela esperança de ter família. Tribuna Hoje [Internet]. 2014 [citado 09 maio 2017]. Disponível em: https://tribunahoje.com/

41. Doença rara: aos 17 anos, jovem descobre que não tem vagina. Correio do Estado [Internet]. 2013 [citado 09 maio 2017]. Disponível em: https://www.correiodoestado.com.br/noticias/doenca-rara-aos17-anos-jovem-descobre-que-nao-tem-vagina/199610/

42. Elson J. Hormonal Hierarchy: Hysterectomy and Stratified Stigma. Gend Soc.2003; 17:750-70. 
43. Fortes P. Ética e saúde: questões éticas, deontológicas e legais, tomada de decisões, autonomia e direito do paciente. São Paulo: EPU; 1998.

44. Csordas T. Corpo/Significado/Cura. Porto Alegre: Editora da UFRGS; 2008.

45. Wolf M. Teorias das comunicações de massa. 4. ed. São Paulo: Editora WWF Martins Fontes; 2009.

46. Ernst ME, Sandberg DE, Keegan C, Quint EH, Lossie AC, Yashar BM. The Lived Experience of MRKH: Sharing Health Information with Peers. J Pediatr Adolesc Gynecol. 2016;29(2):154-8.

47. Le Breton D. Antropologia da dor. São Paulo: Fap-Unifesp; 2013.

48. Estadão Conteúdo. Mulher de 28 anos recebe útero de doadora morta. Correio Popular [Internet]. 2016 [citado 09 maio 2017]. Disponível em: http://correio.rac.com.br/mobile/materia historico. php?id=452414

49. Silva Y. Gerado pela avó, bebê é registrado por pais. A Tarde [Internet]. 2015 [citado 09 maio 2017]. Disponível em: http://atarde.uol.com.br/bahia/noticias/1707889-gerado-pela-avo-bebe-e-registrado-por-pais

50. Paciente que recebeu vagina artificial conta que técnica mudou sua vida. Tribuna Hoje [Internet]. 2014 [citado 09 maio 2017]. Disponível em: https://tribunahoje.com/.

51. Transplante de útero é possibilidade para substituir barriga de aluguel. Tribuna Hoje [Internet]. 2015 [citado 09 maio 2017]. Disponível em: https://tribunahoje.com/.

52. Vieira JR. Aos 17 anos, jovem inglesa descobre que não tem vagina. Folha do Espírito Santo [Internet]. 2013 [citado 09 maio 2017]. https://www.folhadoes.com/noticia/especial-publicitario-estilo/1307/aos17-anos-jovem-inglesa-descobre-que-nao-tem-vagina

53. Pesquisadores norte-americanos registram avanços no transplante de útero. Correio Braziliense [Internet]. 2016 [citado 09 maio 2017]. Disponível em: https://www.correiobraziliense.com.br/app/ noticia/ciencia-e-saude/2016/10/06/interna ciencia saude,552056/pesquisadores-norte-americanosregistram-avancos-no-transplante-de-ute.shtml

54. Coêlho AFVCMB, Costa AKG, Lima MG. Da ética principialista para a bioética de intervenção: sua utilização na área da saúde. Tempus - Actas Saúde Coletiva [Internet]. 2013 [citado em 2019 maio 17]; 7(4):239-53. doi: http://dx.doi.org/10.18569/tempus.v7i4.1432

55. Feenberg A. Critical theory of technology. New York: Oxford University Press; 1991.

56. Sherwin S. No longer patient: Feminist ethics and health care. Philadelphia: Temple University Press; 1992.

57. Azevedo RF, Lopes RLM. Concepção de corpo em Merleau-Ponty e mulheres mastectomizadas. Rev. Bras. Enf. 2010:63(6):1067-1070. doi: http://dx.doi.org/10.1590/S0034-71672010000600031

58. Mattos RS, Luz MT. Sobrevivendo ao estigma da gordura: um estudo socioantropológico sobre obesidade. Physis. 2009;19(2):489-507. doi http://dx.doi.org/10.1590/S0103-73312009000200014.

59. Villela WV, Monteiro S. Gênero, estigma e saúde: reflexões a partir da prostituição, do aborto e do HIV/ aids entre mulheres. Epidemiol. Serv. Saúde. 2015:24(3):531-540. 2015. doi: http://dx.doi.org/10.5123/ $\underline{\text { S1679-49742015000300019 }}$ 